\title{
Prevalence and Risk Factors for Hypertension, Diabetes and Obesity among Lecturers and Support Staff of Bishop Stuart University in Mbarara, Uganda
}

\author{
Jordan Amanyire1, Mathias Tumwebaze ${ }^{1 *}$, Mauda Kamatenesi Mugisha1, Labani Waswa Bright ${ }^{2}$ \\ ${ }^{1}$ Department of Public Health, Bishop Stuart University, Mbarara, Uganda \\ ${ }^{2}$ Medical Research Council (MRC), Entebbe, Uganda \\ Email: jamanyirem@yahoo.com, ${ }^{*}$ mathiastumwebaze@gmail.com, mkamatenesi@botany.mak.ac.ug, wlabright@gmail.com
}

How to cite this paper: Amanyire, J., Tumwebaze, M., Mugisha, M.K. and Bright, L.W. (2019) Prevalence and Risk Factors for Hypertension, Diabetes and Obesity among Lecturers and Support Staff of Bishop Stuart University in Mbarara, Uganda. Open Journal of Applied Sciences, 9, 126-137.

https://doi.org/10.4236/ojapps.2019.93012

Received: January 28, 2019

Accepted: March 26, 2019

Published: March 29, 2019

Copyright $\odot 2019$ by author(s) and Scientific Research Publishing Inc. This work is licensed under the Creative Commons Attribution International License (CC BY 4.0).

http://creativecommons.org/licenses/by/4.0/

\begin{abstract}
Aim: To establish the prevalence and risk factors for hypertension, diabetes and obesity among teaching and non-teaching staff of Bishop Stuart University, Mbarara-Uganda. Background: None communicable diseases (NCDs) are projected to exceed communicable diseases as the most common causes of death by 2030 in Africa. Most sub-Saharan African countries however lack detailed countrywide data on hypertension and other NCDs risk factors. Cognizant of Uganda's recent inclusion of Hypertension and diabetes in the health policy agenda, this study was conducted among the university staff in a rural setting to provide benchmark information for design of appropriate interventions. Study Design: This was a descriptive cross-sectional, institutional based survey design. Place and duration of the study: This study was conducted among the teaching and none teaching staff of Bishop Stuart University Mbarara, Uganda from 18th April- $6^{\text {th }}$ June 2017. Methodology: A structured questionnaire was used to gather social demographic and risk factors data from the university workers at their work stations. Blood pressure of each participant was measured and Hypertension was defined as systolic BP > 140 and/or diastolic (BP) > $90 \mathrm{mmHg}$. Anthropometric measurements: Body Mass index (BMI) was done by weight in $(\mathrm{Kg})$ and Height in $\left(\mathrm{M}^{2}\right)$ to establish weight levels. Obesity was considered at BMI $>40$. A random Blood Sugar $(\mathrm{RBS})>200 \mathrm{mg} / \mathrm{dl}$ was considered as diabetic. Epi-info version 7 was used to enter data, analyzed using SPSS version 19. Results: A total of 156 University staff aged 25 - 75 years of both sexes, mean age $42 \pm 8$ were interviewed of whom $51 \%$ were males. About $15 \%$ were administrative staff, $55 \%$ teaching staff, $3 \%$ senior lecturers and professors and $25 \%$ non-teaching staff.
\end{abstract}


The prevalences of Hypertension, Diabetes, and obesity were 7.7\%, 16\%, and $28 \%$ respectively. But also majority $(60.2 \%)$ were found at risk of developing both hypertension and diabetes. Less than $20 \%$ of the participants were knowledgeable on causes, signs and symptoms and preventive measures for Hypertension but had moderate knowledgeable of the risk factors, the most frequently mentioned risk by $71 \%$ was lack of exercise. Despite the awareness of risk factors, majority (61.3\%) had not done any form of exercise and $64.1 \%$ had not had regular Blood pressure check ups. The study also demonstrated a statistically significant relationship between those aged more than 40 years and having hypertension $\left(\mathrm{X}^{2}=5.82, \mathrm{P}=0.015, \mathrm{OR}=4.2\right)$. Likewise the risk of Diabetes increased with increasing age. Lecturers aged 40 years and above were 5.6 times likely to have diabetes compared to those aged less than 40 years $\left(\mathrm{OR}=5.6, \mathrm{X}^{2}=16, \mathrm{P}=0.0005\right)$. A significant number of respondents $57 / 156(36.5 \%)$ reported history of HPT among their family members. Prevalence of obesity and overweight was observed higher in senior administrative staff and lecturers than in lower cadre staff $49 \%$ and $34 \%(\mathrm{p}<0.01)$. Conclusion: Hypertension, Diabetes and obesity are conditions prevalent among the teaching and none teaching staff of BSU, but knowledge on risk factors, clinical presentation and preventive strategies is limited. Routine physical exercises, periodic body checkups and controlled diet are public Health interventions recommended for control among the university staff.

\section{Keywords}

Prevalence, Risk Factors, Hypertension, Diabetes, Obese, Rural University

\section{Introduction}

Diabetes, hypertension and obesity are among the Non-Communicable Diseases (NCDs) affecting the developed and the developing world. These conditions are often associated with older age groups, but evidence shows that 15 million of all deaths attributed to NCDs which occur between the ages of 30 and 69 years. Of these "premature" deaths, over $80 \%$ are estimated to occur in low- and middle-income countries [1]. The predisposing factors include modifiable behavior risk factors such as unhealthy diet and physical activity of which alone is attributed to 1.6 million deaths annually [2]. The leading metabolic risk factor globally is elevated blood pressure (to which $19 \%$ of global deaths are attributed) [2], followed by overweight and obesity and raised blood glucose.

In Sub Saharan Africa, NCDs are on rather an alarmingly increasing rate. WHO estimates that by the year 2025, about 1.56 billion people will have increased blood pressure [3]. By 2030, low-income countries will have eight times more deaths attributed to NCDs than high-income countries [4]. NCDs are now affecting more people who are in their prime economically productive years, and these deaths are frequently preceded by years of disability [4]. In Africa, hypertension, diabetes and obesity continue to increase among the population [5]. In 
Tanzania for instance, both hypertension and diabetes mellitus are prevalent [6], in addition, the prevalence of obesity amongst adults and children is also increasing at an alarming rate [7]. The reported prevalence of hypertension of systolic $\geq 140$ or diastolic $\geq 90$ ) was $44.4 \%$ for males and of $44.8 \%$ for females while diabetes mellitus prevalence of 9.1\% [7]. In Nigeria alone about 8 million people by 2011 had suffered from hypertension and 4 million had diabetes [8]. A study conducted among staff of the University of Ibadan, Nigeria reported that majority of teaching staff of the University were aware of the diabetes and hypertension [9], however, staff's knowledge of the causes, signs and symptoms, risk factors and complications was not as high as expected considering they were among the highly educated and professional population [9]. In Uganda, Hypertension and diabetes are among the leading prominent non-communicable diseases. A 2014 study done by the Infectious Diseases Institute (IDI) in South Western Uganda indicated that many people do have these diseases but are not aware. The degree of control of hypertension/blood pressure in both rural and urban areas was found to be very low at $27.2 \%$ in the rural areas and at $28.7 \%$ in the urban areas [10]. Hypertension was identified in $40 \%$ of heart failure patients in Mulago hospital as a risk factor for heart disease [11]. The prevalence estimates of diabetes in Uganda range from 8.1\% [12] around Kampala capital city to $9 \%$ in Kasese district western Uganda [13]. Although the Government of Uganda has put in more efforts to control communicable diseases such as HIV/AIDS, little has been done about non-communicable diseases. The current efforts to combat NCDs in Uganda are characterized by inadequate financial budgets for NCDs activities in addition to human resources, equipment, drug supply, and laboratory in capabilities [14]. It is unfortunate that most of the NCDs present in advanced stages and are fatal, this is exacerbated by the culture of poor early health seeking behavior in most African Countries resulting in late poor treatment outcomes for NCDs. It is common knowledge that in higher institutions of learning, most of the University staff have limited time to seek hypertension and diabetes screening services early enough probably because they are unaware that they could be having and living with these diseases.

Currently in Uganda, there are no Ministry of Health targeted health education programs or interventions for institutions of higher learning on NCDs prevention and control. This is on the assumption that individuals in such institutions are highly knowledgeable of these conditions and their risk factors. Besides, there is scarcity of studies on hypertension and diabetes in tertiary institutions in Uganda. Based on this background, the study was undertaken to find out the prevalence of hypertension, diabetes, obesity and their risk factors if any among the teaching and non-teaching staff of Bishop Stuart University, Mbarara Uganda.

\section{Methods}

\subsection{Study Design}

An institutional based, epidemiological study with cross-sectional design was 
conducted among 156 teaching and non-teaching staff of Bishop Stuart University from $18^{\text {th }}$ April- $6^{\text {th }}$ May 2017. Participants were drawn from the three major components of the university staffing i.e., the academic staff, the administration and the non-teaching staff.

\subsection{Sample Size}

Bishop Stuart University had a total of 260 teaching and non-teaching staff by March 2017 according to the Human resource report for the beginning of semester 11 of 2016/2017 academic year. Aware of the target population, Krejcie and Morgan table 1970 [15] for sample sizes was used to determine a representative sample size. Morgan and Krejicie table shows that $\mathrm{N}$ represents population size, and $\mathrm{n}=$ Sample size: hence from the table $\mathrm{N}=260$, a corresponding sample size (n) of 156 was extracted and used as the study sample size.

\subsection{Sampling Procedure and Selection of Respondents}

Stratified sampling was used to categories the study population into 3 components i.e. teaching staff, administrative staff, and support staff. Teaching staff members were drawn from all the departments and a total of 85 staffs (teaching Assistants, lecturers, senior lecturers and professors) were by simple random sampling identified. Being a small population, all the administrative staffs (25) in number were incorporated in the study except those on leave. The non-teaching staff included compound working staff, security department staff and drivers, a total of 42 non-teaching staff were randomly selected and incorporated in the study.

\subsection{Data Collection Tools}

In this study, pre-designed and pre-tested, interviewer-administered structured questionnaire with open-ended and closed questions was used. The first part of our study tool focused on respondents' demographic, socioeconomic, and knowledge while the second part of the tool focused on respondents' physical body measurements (anthropometry). Three (3) research assistants were trained to administer the questionnaires and take anthropometric measurements. Training was done by the principle investigator for a period of 2 days a laboratory Technician was co-opted on the team to collect and process the collected samples.

\subsection{Data Collection Procedure}

Study subjects were interviewed in their work place setting after explaining the academic nature of this research and they were assured that information collected would be kept confidential. Two (2) attempts were made to interview a particular individual if the person could not be accessed the first time or (s)he was suffering from any acute illness on the day of the first visit. Blood pressure was measured on the upper left arm after at least 10 minutes of rest using a 
mercury sphygmomanometer in millimeters of mercury ( $\mathrm{mmHg}$ ). During the study, individuals with blood pressure level more than or equal to $140 / 90 \mathrm{mmHg}$ were advised to visit the University Clinic for further treatment.

Weight was measured in kilograms $(\mathrm{kg})$ using calibrated weighing scales with participants lightly clothed. Height was measured in meters using standard height meter by participants standing upright on the height meter, BMI was computed using a Reference Scale BMI: Below 16 = severe malnutrition, 16 $16.99=$ moderate malnutrition, $17-18.4=$ mild malnutrition, Normal weight $=$ $18.5-25,25-29.99=$ overweight grade $1.30-39.99=$ overweight grade 2 (obesity), above 40 = overweight grade 3 (severe obesity).

Random blood sugar sample was drawn from every participant and measured using glucometer strips following the Reference Scale for Normal Random Blood Sugar as equal or less than $200 \mathrm{mg} / \mathrm{dl}$. Any participant without history of diabetes presenting with random blood sugar of $>200 \mathrm{mg} / \mathrm{dl}$ was identified as having diabetes.

\subsection{Data Management and Analysis}

Data were entered, cleaned and edited for inconsistencies in Epi-info version 7. There after a Statistical Package for Social Scientists (SPSS) version 19 was used for analysis. Descriptive and analytical statistics were used to summarize the data. Descriptive statistics involved the use of frequencies, proportions and tables. Analytical statistics through bivariate analysis and multivariate logistic regression were performed to identify factors associated with the occurrence of hypertension, overweight and obesity. The chi square test was used in determining statistically significant associations while factors with p-values $<0.05$ were included in the logistic regression model. Adjusted odds ratios (AORs) were determined with $95 \%$ confidence interval (CI) to identify independent factors.

\subsection{Ethical Considerations}

Guidance to do research was sought from the Institutional Review Committee that reviewed all the protocols. Informed consent was sought from the respondents before taking their blood pressure, weight, height and getting blood samples from them. Respondents consented to the data collection process. Standard Operating Procedures (SOPs) for checking blood pressure, Weight, Height, blood sugar were considered.

\section{Results}

This study set out to find the prevalence of hypertension, diabetes and obesity among staff of Bishop Stuart University, proportion of staff at a risk of developing hypertension, diabetes and obesity and also to examine the university staff's knowledge on risk factors, complications and preventive measures for the mentioned three conditions.

A total of 156 study respondents participated in the study mean age $42.4 \mathrm{SD} \pm$ 
9 years. Eighty percent of the samples were males and $48 \%$ were females. Overall prevalence of hypertension in the study subjects was $7.1 \%$. But $9.6 \%$ had systolic and diastolic blood pressure of $140 \mathrm{~mm} \mathrm{Hg}$ and $90 \mathrm{mmHg}$ respectively with high likely hood of being hypertensive if the blood pressure persisted. The Diabetic status of the staffs was established based on random blood sugar. About $16.7 \%$ of respondents were diabetic with high blood glucose $>7 \mathrm{mmol} / \mathrm{dl}$, majority $83.3 \%$ were not diabetic. About a third (27.6\%) of the respondents had family members with diabetes, a risk factor for the study subjects to develop diabetes. The overall prevalence of obesity in the study was $28 \%$ (44/156) (Table 1 ).

Table 2 provides substantial evidence of study subjects at high risk of developing HPT, Diabetes and Obesity. Majority 80/156 (61.3\%) were not doing any form of exercise while 100/156 (64.1\%) had not had regular blood pressure check ups. A third 57/156 (33.1\%) reported history of HPT among their family members. Smoking practice was among 21 (13.5\%) responds and 22/156 (14.1\%) accepted regularly taking of alcohol.

About three quarters (74\%) of the staff were not aware of Visual Problems as Sign of Diabetes, 69\% not aware of Excess thirst as a Sign of Diabetes and 68\% were not aware of the need for regular blood glucose checkups as a preventive strategy (Table 3).

\section{Discussion}

This cross-sectional study being the first of its kind to explore the knowledge and prevalence of hypertension, diabetes and obesity among the staff of Bishop Stuart University in western Uganda, one most important finding of the study is

Table 1. (a) Demographic characteristics of study subjects and prevalence of Hypertension; (b) Demographic characteristics of study subjects and prevalence of Diabetes; (c) Demographic characteristics of study subjects and prevalence of obesity.

(a)

\begin{tabular}{ccccc}
\hline Characteristics & $\begin{array}{c}\text { Hypertension } \\
\mathbf{n}(\%)\end{array}$ & $\begin{array}{c}\text { Non-Hypertension } \\
\mathbf{n}(\%)\end{array}$ & $\begin{array}{c}\text { Total } \\
\mathbf{n}(\%)\end{array}$ & $\begin{array}{c}\text { Chi-square and } \\
\text { p-value }\end{array}$ \\
\hline Age $\geq 40$ years & $6(16 \%)$ & $32(84 \%)$ & $38(25 \%)$ & $0 \mathrm{R}=4.23, \mathrm{X}^{2}=5.82$ \\
$<40$ years & $5(4 \%)$ & $113(96 \%)$ & $118(75 \%)$ & $\mathrm{RR}=0.07,{ }^{*} \mathrm{p}=0.015$ \\
Total & $11(7 \%)$ & $145(93 \%)$ & & \\
Religion Protestant & $7(5.6 \%)$ & $118(94.4 \%)$ & $120(64 \%)$ & $0 \mathrm{R}=0.5, \mathrm{X}^{2}=1.3$ \\
Other religions & $4(11.1)$ & $32(89 \%)$ & $36(36 \%)$ & $\mathrm{RR}=0.5, \mathrm{p}=0.248$ \\
$\quad$ Total & $11(7.1 \%)$ & $145(92.9 \%)$ & & \\
Gender: Male & $8(10 \%)$ & $72(90 \%)$ & $80(52 \%)$ & $0 \mathrm{R}=2.7, \mathrm{X}^{2}=0.14$ \\
$\quad$ Female & $3(4 \%)$ & $73(96 \%)$ & $76(48 \%)$ & $\mathrm{RR}=2.53, \mathrm{p}=0.14$ \\
Role: Technical staff & $10(8.8 \%)$ & $103(91.2 \%)$ & $113(72 \%)$ & $0 \mathrm{R}=4.0, \mathrm{X}^{2}=2.02$ \\
support staff & $1(2.3 \%)$ & $42(97.6 \%)$ & $43(28 \%)$ & $\mathrm{RR}=3.80, \mathrm{p}=0.15$ \\
Total & $11(7.1 \%)$ & $145(92.9 \%)$ & & \\
Technical staff & & & & \\
$<$ master's degree & $5(5.8 \%)$ & $81(92.2 \%)$ & $86(73 \%)$ & $0 \mathrm{R}=0.65, \mathrm{X}^{2}=0.44$ \\
$\geq$ Master's degree & $6(8.57 \%)$ & $64(91.4 \%)$ & $70(27 \%)$ & $\mathrm{RR}=0.67, \mathrm{p}=0.50$ \\
$\quad$ Total & $11(7.1 \%)$ & $145(92.9 \%)$ & &
\end{tabular}

The overall prevalence rate of Hypertension in the study $7.1 \%$ (11/156). 
(b)

\begin{tabular}{ccccc}
\hline Characteristics & $\begin{array}{c}\text { Diabetic } \\
\mathbf{n}(\%)\end{array}$ & $\begin{array}{c}\text { Non-diabetic } \\
\mathbf{n}(\%)\end{array}$ & $\begin{array}{c}\text { Total } \\
\mathbf{n}(\%)\end{array}$ & $\begin{array}{c}\text { Chi-square, p-value, } \\
\text { RR, } \& \text { OR }\end{array}$ \\
\hline Age $\geq 40$ years & $14(36.8)$ & $24(64 \%)$ & $38(25 \%)$ & 0R $=5.6, \mathrm{X}^{2}=16$, \\
$<40$ years & $11(9.4)$ & $107(90.6 \%)$ & $118(75 \%)$ & ${ }^{*} \mathrm{p}=0.0005$ \\
Total & $25(16 \%)$ & $131(83 \%)$ & & \\
Religion Protestant & $20(16.6 \%)$ & $100(83.4 \%)$ & $120(64 \%)$ & $\mathrm{OR}=1.24, \mathrm{X}^{2}=0.158$ \\
Other religions & $5(13.8 \%)$ & $31(86.2 \%)$ & $36(36 \%)$ & $\mathrm{P}=0.690$ \\
Total & $25(16 \%)$ & $131(83 \%)$ & & \\
Gender. Male & $16(20 \%)$ & $64(80 \%)$ & $80(52 \%)$ & $0 \mathrm{R}=1.86, \mathrm{X}^{2}=1.942$ \\
Female & $9(11.8 \%)$ & $67(88.2 \%)$ & $76(48)$ & ${ }^{*} \mathrm{p}=0.0167$ \\
Total & $25(16 \%)$ & $131(83 \%)$ & & \\
Role: Technical staff & $22(19.4 \%)$ & $91(80 \%)$ & $113(72 \%)$ & $\mathrm{QR}=5.31, \mathrm{X}^{2}=5.832$ \\
support staff & $2(4.3 \%)$ & $41(95.7 \%)$ & $43(28 \%)$ & $\mathrm{RR}=3.939,{ }^{*} \mathrm{p}=0.0157$ \\
Total & $25(16 \%)$ & $131(83 \%)$ & & \\
Technical staff $<$ Mst degree & $10(11.6 \%)$ & $76(88.4 \%)$ & $86(73 \%)$ & $0 \mathrm{R}=0.491, \mathrm{X}^{2}=2.621$ \\
$\geq$ Master's degree & $15(21.3 \%)$ & $55(78.6 \%)$ & $70(27 \%)$ & ${ }^{*} \mathrm{p}=0.096$ \\
Total & $25(16 \%)$ & $131(83 \%)$ & & \\
\hline
\end{tabular}

Of the respondents $25(16.0 \%)$ had high blood sugar levels of $>7 \mathrm{~mm} \mathrm{~mol} / \mathrm{l}$ hence diabetic. ${ }^{*} \mathrm{p}<0.05$, shows the association being due to chance is less than $5 \%$. Hence a statistically significant association established.

(c)

\begin{tabular}{ccccc}
\hline Characteristics & $\begin{array}{c}\text { Obese } \\
\mathbf{n}(\%)\end{array}$ & $\begin{array}{c}\text { Non-Obese } \\
\mathbf{n}(\%)\end{array}$ & $\begin{array}{c}\text { Total } \\
\mathbf{n}(\%)\end{array}$ & $\begin{array}{c}\text { Chi-square and } \\
\mathbf{p} \text {-value }\end{array}$ \\
\hline Age $\geq 40$ years & $18(42 \%)$ & $20(53 \%)$ & $118(75 \%)$ & QR: $3.5, \mathrm{X}^{2}=10.6$ \\
$<40$ years & $24(20 \%)$ & $94(79 \%)$ & $38(25 \%)$ & $\mathrm{RR}=2.25,{ }^{*} \mathrm{p}=0.0011$ \\
Total & $42(27 \%)$ & $114(79 \%)$ & & \\
Religion: Protestant & $30(25 \%)$ & $90(75 \%)$ & $120(64 \%)$ & QR: $0.5, \mathrm{X}^{2}=2.63$ \\
Other Religions & $14(38 \%)$ & $22(61 \%)$ & $36(36 \%)$ & $\mathrm{RR}=0.62, \mathrm{p}=0.104$ \\
Total & $44(28 \%)$ & $112(72 \%)$ & & \\
Gender: Male & $32(40 \%)$ & $48(60 \%)$ & $80(52 \%)$ & $\mathrm{QR}: 3.5, \mathrm{X}^{2}=11.2$ \\
Female & $12(15.8 \%)$ & $64(84.2 \%)$ & $76(48)$ & $\mathrm{RR}=2.5,{ }^{*} \mathrm{p}=0.0078$ \\
Total & $44(28 \%)$ & $112(72 \%)$ & & \\
Role: Technical staff & $38(33.6 \%)$ & $75(66.4 \%$ & $113(72 \%)$ & $\mathrm{QR}: 3.1, \mathrm{X}^{2}=5.9$ \\
support staff & $6(13.9 \%)$ & $37(88.1 \%)$ & $43(28 \%)$ & $\mathrm{RR}=2.4,{ }^{*} \mathrm{p}=0.014$ \\
Total & $44(28 \%)$ & $112(72 \%)$ & & \\
Technical staff & $16(19.5 \%)$ & $60(80.5 \%)$ & $86(73 \%)$ & $\mathrm{QR}: 0.39, \mathrm{X}^{2}=6.45$ \\
$<$ Master's degree & $28(37.8 \%)$ & $42(62.3 \%)$ & $70(27 \%)$ & $\mathrm{RR}=0.62,{ }^{*} \mathrm{p}=0.011$ \\
$\geq$ Master's degree & $44(28 \%)$ & $112(72 \%)$ & & \\
Total & &
\end{tabular}

The overall prevalence of obesity in the study was $28 \%(44 / 156)$.

that all the three conditions were prevalent among the university staff i.e. 7.1\% with hypertension, $16.7 \%$ were diabetic and $28 \%$ with obesity.

\subsection{Prevalence of Hypertension}

Comparatively, the prevalence of hypertension in the current study is lower than the prevalence of hypertension (26.1\%) observed in west Bengal rural community in 2017 [16]. Similarly, recent studies conducted in south western Nigeria also reported a slightly higher prevalence of (31.6\%) [17], 20.8\% [18] and 26.4\%, similar higher prevalence of hypertension 28.3\% [19] was reported in Ethiopia 
Table 2. Proportion of staff at a risk of developing hypertension, diabetes and obesity.

\begin{tabular}{cccc}
\hline Risk factor HPT, Diabetes and Obesity & Yes & Frequency & Percent \\
\hline Doing some form of exercises & Yes & 76 & $48.7 \%$ \\
Regular Blood pressure check up & No & 80 & $51.3 \%$ \\
History of Hypertension in a family & Yes & 56 & $35.9 \%$ \\
& No & 100 & $64.1 \%$ \\
Respondent smoking status & Yes & 57 & $33.1 \%$ \\
Alcohol consumption status & No & 99 & $63.4 \%$ \\
& Yes & 21 & $13.5 \%$ \\
Total cholesterol levels above range (200 - 260) & No & 135 & $86.5 \%$ \\
& Yes & 22 & $14.1 \%$ \\
& No & 134 & $85.9 \%$ \\
& No & 4 & $2.6 \%$ \\
& & 152 & $97.4 \%$ \\
\hline
\end{tabular}

Table 3. Respondents knowledge and awareness of HPT, Diabetes and obesity conditions.

\begin{tabular}{ccc}
\hline \multicolumn{4}{c}{ Respondents knowledge and awareness of Features of Diabetes } & \\
\hline Awareness of Passing a lot of Urine as a Sign of Diabetes & Frequency & Percent \\
\hline Yes & 84 & 53.8 \\
No & 72 & 46.2 \\
\hline Awareness of Visual Problems as Sign of Diabetes & & \\
\hline Aware & 40 & $26 \%$ \\
Not aware & 116 & $74 \%$ \\
\hline Awareness of Excess Thirst as a Sign of Diabetes & & \\
\hline Aware & 48 & $31 \%$ \\
Not aware & 108 & $69 \%$ \\
\hline Respondents awareness of Healthy Checks to Prevent Future Diabetes & \\
\hline & 49 & $31 \%$ \\
& 107 & $68 \%$ \\
\hline
\end{tabular}

and $32 \%$ in Ghana [20]. Although these studies were done in the general community while ours was done in a university setting, this may not fully explain why there is such a big difference. The observed difference could be due to the fact that three quarters (76.1\%) of our study subjects were under forty five years of age. Several studies including ours have demonstrated a rising trend in hypertension affecting adults [21] [22]. Specifically, our study demonstrated a statistically significant relationship between those aged more than 40 years and having hypertension $\left(\mathrm{X}^{2}=5.82, \mathrm{P}=0.015, \mathrm{OR}=4.2\right)$. A noted clear sharp contrast to our study findings however, is that observed from Kulandaivelan, (2015) where 
the overall prevalence of Hypertension among the university employees in India was found to be $37 \%$. [22], probablythe difference in life styles could explain the sharp difference. According to WHO (2005) [23], the risk of hypertension is usually higher in the obese and overweight. In this study $32 \%$ were overweight $\left(\right.$ BMI $25<30 \mathrm{~kg} / \mathrm{m}^{2}$ while $28.2 \%$ were obese BMI $>30 \mathrm{~kg} / \mathrm{m}^{2}$. In general, $\mathrm{n}=94$ (60.2\%) a proportion of 0.6 was at risk of developing hypertension and according to WHO 2005 report, this rate is higher than that of USA (50\%/0.5 proportion) and Australia 37\%/0.37. Whereas this appears to be an alarming risk among university staff to developing hypertension in a rural a setting, this finding concurs with recent global estimated rates of obesity [24] that has tripled in the developing countries as a result of people adopting a western lifestyle that involve decreased physical activity and overconsumption of cheap energy-dense foods. In our study only $48.7 \%$ of the University staff were practicing daily exercises to prevent hypertension.

\subsection{Diabetes}

This study established the prevalence of diabetes among university staff as $16.1 \%$, this finding is not much different from $15 \%$ prevalence in Nepal among people aged 20 years and above according to Nepal Diabetes Association (NDA) [25]. In contrast however, cross-sectional studies previously done around towns close to Kampala city showed a low prevalence of $8.1 \%$ [26] and 9\% from studies on foot hills of Rwenzori Mountains in western Uganda [13]. These differences could be as a result of heterogeneity of diabetes across population structures and difference in life styles given the fact that our study focused on the elite group only while the rest were focusing on general population.

Risk factors for Diabetes among the study subjects included, age, sex, obesity, and family History. In this study, lecturers aged 40 years and above were 5.6 times likely to have diabetes compared to those aged less than 40 years $(\mathrm{OR}=$ $\left.5.6, \mathrm{X}^{2}=16, \mathrm{P}=0.0005\right)$. The strong association between advancing age and diabetic condition was consistent with other studies [12] [27]. In this study being a male was also statistically associated with diabetes compared to females $(\mathrm{OR}=$ $1.86, \mathrm{P}=0.0167$ and $\mathrm{X}^{2}=1.942$ ).

\subsection{Obesity}

The overall prevalence of obesity in this study was $28 \%$ and overweight at $32.15 \%$ (BMI $\left(25<30 \mathrm{~kg} / \mathrm{m}^{2}\right)$. This is slightly higher than $25 \%$ among Civil Servants in Nepal. In this study $32.7 \%$ had practiced physical exercise to prevent future diabetes while majority (67.3\%) did not. This finding is in contrast with findings of William K.M (2010) in the Kenyan study where a relatively bigger percent of respondents (72\%) had not participated in regular physical exercise. Studies done elsewhere have also demonstrated that physical inactivity is a major risk factor diabetes and Hypertension. 


\section{Conclusion}

In this study, the prevalence of Hypertension among the staff was 7.1\%; diabetes was $16 \%$ and obesity $28 \%$. Only $16 \%$ of respondents were knowledgeable about cause, signs and symptoms and risk factors for Hypertension. Notwithstanding society perception of university lecturers as highly knowledgeable and aware group of most social issues as well as health matters, the prevalence of the three non-communicable conditions studied was high amidst limited knowledge. This therefore demonstrates a need for high level awareness campaigns to the university staff about non-communicable diseases and the need for regular health checkups. Routine physical exercises and controlled diet are public health interventions recommended for control of none communicable diseases among the university staff.

\section{Limitations of the Study}

These findings are based on the survey data collected from staff from one university in Uganda. Findings from more than one university could have demonstrated a different picture. Much as the risk and associated factors to Hypertension, Diabetes and Obesity were identified, detailed analysis on the confounding factors like smoking and excessive alcoholism was not done. The researcher was establishing the diabetic status of the participant basing on random blood sugar only. Other studies have demonstrated diabetic status of participants by doing both random blood sugar and fasting blood sugar to get conclusive results.

Mixed data collection techniques (quantitative and qualitative) could have been used, i.e. in depth interviews or FGDs could have helped to explore the participant's knowledge of the three conditions studied and their risk factors. Only structured (quantitative) data collection tool was used.

\section{Acknowledgements}

We thank the three research assistants and laboratory technician who collected data and processed it. This study was funded by University (BSU) Research and Grants Committee.

\section{Conflicts of Interest}

There are no competing interests.

\section{References}

[1] World Health Organization (2017) Non-Communicable Disease Progress Monitor 2017.

[2] GBD (2016) Risk Factors Collaborators. Global, Regional, and National Comparative Risk Assessment of 79 Behavioural, Environmental and Occupational, and Metabolic Risks or Clusters of Risks, 1990-2015: A Systematic Analysis for the Global Burden of Disease Study 2015. The Lancet, 388, 1659-1724.

https://doi.org/10.1016/S0140-6736(16)31679-8 
[3] WHO (2011) WHO Maps: Non-Communicable Disease Trend in All Countries. World Health Global Report, World Health Organization.

[4] Nikolic, I.A., Stanciole, A.E. and Zaydman, M. (2011) Chronic Emergency: Why NCDs Matter. World Bank Health, Nutrition and Population Discussion Paper.

[5] Mufunda, J., Chatora, R., Ndambakuwa, Y., Nyarango, P., Kosia, A., Chifamba, J. and Filipe, A. (2006) Emerging Non-Communicable Disease Epidemic in Africa: Preventive Measures from the WHO Regional Office for Africa. Ethnicity and Disease, 16, 521-526.

[6] Mayige, M., Kagaruki, G., Ramaiya, K. and Swai, A. (2011) Non-Communicable Diseases in Tanzania: A Call for Urgent Action. Tanzania Journal of Health Research, 13, 378-386.

[7] Kisembo, P. (2006) Overweight, Obesity Major Health Problems in Tanzania. The Guardian News Paper, 6.

[8] Health Reform Foundation of Nigeria (HERFON) (2011) Diabetes to Top Cause of Death in 2015. http://www.Vanguardngr.com/-2011/10/

[9] Abdullahi, A.A. and Amzat, J. (2011) Knowledge of Hypertension among the Staff of University of Ibadan, Nigeria. Journal of Public Health and Epidemiology, 3, 204-209.

[10] Kayima, J. (2006) Hypertension in Uganda: Prevalence, Awareness, Control and Some Associated Factors in Wakiso District. MMed. Thesis.

[11] Achadu, C. (2002) The Pattern of Cardiac Disease and Etiology of Cardiac Failure among Patients Attending Mulago Hospital Cardiac Clinic and Medical Wards. MMed. Thesis.

[12] Maher, D., Waswa, L., Baisley, K., Karabarinde, A., Unwin, N. and Grosskurth, H. (2011) Distribution of Hyperglycaemia and Related Cardiovascular Disease Risk Factors in Low-Income Countries: A Cross-Sectional Population-Based Survey in Rural Uganda. International Journal of Epidemiology, 40, 160-171.

[13] Mondo, C.K., Otim, M.A., Akol, G., Musoke, R. and Orem, J. (2013) The Prevalence and Distribution of Non-Communicable Diseases and Their Risk Factors in Kasese District, Uganda. Cardiovascular Journal of Africa, 24, 52-57.

[14] Rogers, H. (2014) Assessment of the Capacity of Ugandan Health Facilities, Personnel, and Resources to Prevent and Control Non-Communicable Diseases. Master's Thesis, Yale School of Public Health.

[15] Krejcie, R.V. and Morgan, D.W. (1970) Determining Sample Size for Research Activities. Educational and Psychological Measurement, 30, 607-610.

[16] Karmakar, N., Naiya, S., Saha, I., Sinha, R., Sahoo, S.K. and Dasgupta, A. (2017) Prevalence of Hypertension and Its Socio-Demographic Factors among Adult Population in a Rural Community of Singur Block, Hooghly District, West Bengal. International Journal of Community Medicine and Public Health, 4, 2736-2740. https://doi.org/10.18203/2394-6040.ijcmph20173317

[17] Asekun-Olarinmoye, E.O., Akinwusi, P.O., Adebimpe, W.O., Isawumi, M.A., Hassan, M.B., Olowe, O.A., Makanjuola, B., lebiosu, C.O. and Adewole, T.A. (2013) Prevalence of Hypertension in the Rural Adult Population of OsunState, Southwestern Nigeria.

[18] Oladapo, O.O., Salako, L., Sadiq, L., Soyinka, K. and Falase, A.O. (2013) Knowledge of Hypertension and Other Risk Factors for Heart Disease among Yoruba Rural Southwestern Nigerian Population. British Journal of Medicine \& Medical Research, 3, 993-1003. https://doi.org/10.9734/BJMMR/2013/2685 
[19] Adebayo, R.A., Balogun, M.O., Adedoyin, R.A., Obashoro-John, O.A., Bisiriyu, L.A. and Abiodun, O.O. (2013) Prevalence of Hypertension in Three Rural Communities of Ife North Local Government Area of Osun State, South West Nigeria. International Journal of General Medicine, 6, 863-868. https://doi.org/10.2147/IJGM.S51906

[20] Amoah, A.G.B. (2003) Hypertension in Ghana: A Cross-Sectional Community Prevalence Study in Greater Accra. Ethnicity \& Disease, 13, 310-315.

[21] Mittal, P. and Mittal, Y. (2013) Prevalence of Hypertension among Rural Population of Doiwala Block, Dehradun, Uttarakhand India. Recent Research in Science and Technology, 5, 21-24.

[22] Kulandaivelan, S. and Yamini (2015) Prevalence and Determinants of Hypertension among University Employees. Journal of Exercise Science and Physiotherapy, 11, 1.

[23] Narkiewicz, K. (2005) Obesity and Hypertension. The Issue Is More Complex than We Thought. NDT, Oxford University Press on behalf of ERA-EDTA, Oxford.

[24] ParvezHossain, M.D., BisherKawar, M.D. and Meguid El Nahas, M.D. (2007) Obesity and Diabetes in the Developing World a Growing Challenge. The New England Journal of Medicine, 356, 213-215.

[25] Paudel, V.P. (2017) Prevalence of Hypertension and Diabetes Mellitus in Political Cadres of Nepal. Journal of College of Medical Sciences-Nepal, 13, 345-349. https://doi.org/10.3126/jcmsn.v13i3.17694

[26] Lasky, D., Becerra, E., Boto, W., Otim, M. and Ntambi, J. (2002) Obesity and Gender Differences in the Risk of Type 2 Diabetes Mellitus in Uganda. Nutrition, 18, 417-421.

[27] Christensen, D.L., Friis, H., Mwaniki, D.L., et al. (2009) Prevalence of Glucose Intolerance and Associated Risk Factors in Rural and Urban Populations of Different Ethnic Groups in Kenya. Diabetes Research and Clinical Practice, 84, 303-310. 